Research Paper:

\title{
Self-Management and Its Related Factors Among crosslark People With Epilepsy Referring to Iranian Epilepsy Association
}

Alice Khachian', Mahnaz Seyedoshohadaee ${ }^{1}$, Agha Fatemeh Hosseini' ${ }^{2}$, Marzieh Shamsi ${ }^{3}$, Narges Bahiraei ${ }^{{ }^{*}}$

1. Department of Medical Surgical Nursing, School of Nursing and Midwifery, Iran University of Medical Sciences, Tehran, Iran

2. Department of Biostatistics, School of Public Health, Iran University of Medical Sciences, Tehran, Iran.

3. Department of Rehabilitation Nursing, School of Nursing and Midwifery, Iran University of Medical Sciences, Tehran, Iran.

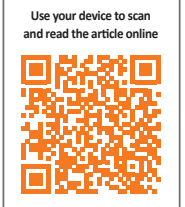

Cittation: Khachian, A. et al., 2017. Self-Management and Its Related Factors Among People With Epilepsy Referring to Iranian Epilepsy Association. Journal of Client-Centered Nursing Care, 3(2), pp. 147-152. https://doi.org/10.32598/jccnc.3.2.147

doi ${ }^{\circ}$ : https://doi.org/10.32598/jccnc.3.2.147

Article info:

Received: 15 Nov. 2016

Accepted: 27 Feb. 2017
Keywords:

Education, Epilepsy, Self-management
A B S T RA C T

Background: People with chronic diseases, including epilepsy, need to learn self-management behaviors so as to control their disease and reduce its complications. The present study aims to determine how people with epilepsy self-manage the disease.

Methods: The present research was a descriptive-correlational study conducted on 100 patients with epilepsy who had been referred to the Iranian Epilepsy Association in Tehran in January 2016 and met the inclusion criteria. The research tools included the disease profile form, demographic questionnaire, and self-management behaviors questionnaire for people with epilepsy. Statistical calculations were performed using SPSS software version 22.

Results: It was found that $85.6 \%$ of the subjects had low self-management and $14.4 \%$ had moderate to high self-management. Independent t-test showed a significant relationship between self-management and marital status $(\mathrm{P}<0.05)$. There was no significant difference between total self-management score and other cognitive characteristics $(\mathrm{P}>0.05)$. A negative and significant relationship was observed between age and self-management $(\mathrm{P}<0.05)$. There was no significant difference between total self-management score and other cognitive characteristics $(\mathrm{P}>0.05)$.

Conclusion: The findings indicate that educational interventions should be conducted to meet the educational needs of people with epilepsy in future studies.

\section{Background}

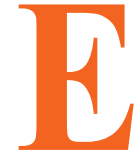

pilepsy is a chronic neurological disorder that imposes many costs on individuals and society. In Iran, epilepsy is prevalent in 1.2 to 4 individuals per 1,000 people (Akbarbegloo et al. 2015). People with epilepsy have limited information on their disease and thus, are poorly adapted to their conditions (Edward et al. 2015). Since epilepsy has a devastating effect on the lives of the affected people, these

* Corresponding Author:

Narges Bahiraei, MSc. Student

Address: Department of Medical Surgical Nursing, School of Nursing and Midwifery, Iran University of Medical Sciences, Tehran, Iran.

Tel: +98 (918) 5094808

E-mail: narges_bahiraei@yahoo.com 
people may feel like a burden on their family and community (Sawangchareon et al. 2013). The lack of awareness of the disease and its social stigma often result in an increased risk of personal injury premature death (Mameniskiene, Sakalauskaite Juodeikiene \& Budrys 2015). The treatment and control of chronic diseases, including epilepsy, involve learning how to live with symptoms or disability and being accustomed to the resultant identity change.

Another part of the treatment includes lifestyle changes and implementation of necessary treatments to control symptoms and prevent complications (Hinkle \& Cheever 2014). Also, individuals with epilepsy should take preventive care to improve disease control and reduce the risk of complications (Pascual et al. 2015). The lack of adherence to treatment may result in further symptoms, more functional disability, increased use of healthcare services, and increased related costs (Fitzsimons et al. 2012). People with epilepsy should be educated so as to identify and manage hysteria stimuli in their surroundings, employ strategies to remember the use of antiepileptic drugs, and take some measures to minimize the risks of hysteria (Merianos et al. 2014). However, people with epilepsy often receive little support from healthcare services regarding self-management behaviors, which results in such people, especially those with low education levels, having limited information about their illness (Noble et al. 2015).

Over the past few decades, there has been a steady change in the provision of services to people with mental disorders. Accordingly, the system-based approach of service provision has been gradually replaced by the individual-based approach. Individual support has been widely welcomed and has become a major issue in providing services to people with mental disorders (Ratti et al. 2016). On the other hand, the importance of self-management among people with epilepsy has recently drawn much attention (Clark et al. 2010). Self-management in epilepsy includes taking medication according to prescriptions, regulating the individual's lifestyle to prevent hysteria, tracking hysteria and its side effects, timely meeting your doctor, getting information about hysteria, and treating and managing the disease (Walker et al. 2014). The process of self-management can help the patients to control and better adapt to the disease and increase their self-care capabilities (Miller et al. 2015).

Educational interactions and self-management education in people with epilepsy are not necessarily consistent with standard practices (Edward et al. 2015). This has been substantiated by a previous study that showed the methods currently used in self-management education to be ineffective for people with epilepsy, as it causes people to be independent of others, including their family (Fraser et al. 2011). Therefore, the present study aims to determine the self-management behaviors of people with epilepsy.

\section{Materials \& Methods}

This descriptive-correlational study consisted of all patients with epilepsy admitted to the Iranian Epilepsy Association in 2016. From among them, 100 patients were selected using available sampling method. The average age of the participants in the study was about 35 , and the majority of participants in the study were single and male. The inclusion criteria in this study were 18-60 years of age, having epilepsy for at least one year, taking antiepileptic drugs, having at least one attack in the recent year, and having read and write literacy. The research ethics were observed by getting permission from the Ethics Committee of Iran University of Medical Sciences to the Code of Ethics IR.IUMS.REC1395.9311686005 and the Iranian Epilepsy Association as well as obtaining written consent from the included patients.

Self-reporting questionnaires such as the demographic information questionnaire, the disease profile form, and the self-management questionnaire for epilepsy were used for collecting the data. The selfmanagement questionnaire for epilepsy, developed by Delirio et al. in 2010, included 38 questions about selfmanagement behaviors on five areas of drug self-management, safety and lifestyle management, hysteria management, and information. The questionnaire was rated on a Likert scale from 1 (never) to 5 (always). For this questionnaire, scores less than $50 \%$, i.e. 38114 , indicated low self-management level, between 50 and $75 \%$, i.e. $115-150$, indicated moderate self-management, and above $75 \%$, i.e. $150-190$, indicated high self-management.

In the study of Aliasgharpour et al. (2014), the Cronbach's Alpha coefficient of the questionnaire was determined to be 0.838 . The content validity method was used to determine the scientific validity of the data gathering tool. For this purpose, the tools used in the research were provided to ten faculty members of the Faculty of Nursing and Midwifery of Iran Medical Sciences University. The Cronbach's alpha coefficient was 0.79 in this study. For data collection, the researcher invited the participants to the Epilepsy Association and gave them the questionnaires to complete. The statistical calculations for the information 
Table 1. Mean and standard deviation of age of participants and duration of epilepsy

\begin{tabular}{|c|c|c|c|c|}
\hline Variable & & Percentage & Frequency & Mean (SD) \\
\hline \multirow{3}{*}{ Age } & Under 30 & 1.41 & 37 & \\
\hline & $31-40$ & 2.32 & 29 & $9.34 \pm 748.10$ \\
\hline & Over 40 & 7.26 & 24 & \\
\hline \multirow{3}{*}{ Duration } & Less than 20 months & 7.46 & 42 & \\
\hline & $21-30$ months & 3.33 & 33 & $22 \pm 312.12$ \\
\hline & More than 30 months & 20 & 18 & \\
\hline
\end{tabular}

obtained in this study were performed using SPSS software version 22 .

\section{Results}

Cognitive and disease information is detailed in Tables 1 and 2. Table 3 shows the results of the difference between the means in the cognitive characteristics of selfmanagement using the independent $t$-test. According to the results of the independent t-test, there is a significant difference between marital status and total self-management $(\mathrm{P}<0.05)$. Accordingly, married patients have higher self-management than unmarried patients. There is no significant difference between total self-management score and other cognitive characteristics $(\mathrm{P}>0.05)$.
Table 4 shows the results of Pearson correlation test between age and duration of disease with total self-management. According to the Table 4, there is a significant and inverse relationship between age and self-management $(\mathrm{P}<0.05)$. This means that with increasing age, total self-management is reduced. Also, no significant relationship could be established between duration of disease and self-management $(\mathrm{P}>0.05)$.

Table 5 shows the results of the mean difference between education level and total self-management using one-way ANOVA. According to the results, there is a significant difference between education level and total self-management $(\mathrm{P}<0.01)$. Table 6 shows the total self-management classification of patients in two low and high classes. Ac-

Table 2. Demographic and disease information

\begin{tabular}{|c|c|c|c|}
\hline Variable & & Percentage & Frequency \\
\hline \multirow{2}{*}{ Gender } & Male & 61 & 8.67 \\
\hline & Female & 29 & 2.32 \\
\hline \multirow{2}{*}{ Marital status } & Single & 47 & 2.52 \\
\hline & Married & 43 & 8.47 \\
\hline \multirow{2}{*}{ Employment status } & Employed & 50 & 6.55 \\
\hline & Unemployed & 40 & 4.44 \\
\hline \multirow{5}{*}{ Education level } & Illiterate & 2 & 2.2 \\
\hline & Elementary & 2 & 2.2 \\
\hline & Secondary school & 27 & 30 \\
\hline & Diploma & 27 & 3.23 \\
\hline & Academic & 38 & 2.42 \\
\hline \multirow{2}{*}{ Medications } & Single medicine & 13 & 4.14 \\
\hline & Multiple medicine & 77 & 6.85 \\
\hline \multirow{2}{*}{ History of epilepsy in the family } & Yes & 39 & 3.43 \\
\hline & No & 51 & 7.56 \\
\hline
\end{tabular}


Table 3. Independent t-test results: Mean differences of cognitive characteristics and self-management

\begin{tabular}{cccccc}
\hline Variable & & Mean & SD & t & P \\
\hline \multirow{2}{*}{ Gender } & Male & Total Self-Management & & 0.200 \\
& Female & 103.75 & 11.71 & 1.292 & 0.000 \\
Marital status & Single & 100.90 & 8.75 & & 0.126 \\
& Married & 98.67 & 10.92 & 9.736 & -1.546 \\
Employment status & Employed & 101.26 & 2.96 & & 0.218 \\
\hline
\end{tabular}

Client-Centered Nursing Care

Table 4. Pearson correlation test between age and duration of disease with total self-management

\begin{tabular}{ccc}
\hline & & Self-Management (Total) \\
\hline Age & Correlation coefficient & -0.208 \\
& Significance level & 0.049 \\
Duration of disease & Correlation coefficient & -0.117 \\
& Significance level & 0.270 \\
\hline
\end{tabular}

Table 5. Mean difference between education level and total self-management

\begin{tabular}{|c|c|c|c|c|c|c|}
\hline \multirow{2}{*}{ Criteria } & \multicolumn{2}{|c|}{ Mean of Squares } & \multicolumn{2}{|c|}{ Degrees of Freedom } & \multirow{2}{*}{$\mathbf{F}$} & \multirow{2}{*}{$\mathbf{P}$} \\
\hline & Intergroup & Intragroup & Intergroup & Intragroup & & \\
\hline Total self-management & 60.919 & 63.80 & 4 & 85 & 404.11 & 000.0 \\
\hline
\end{tabular}

cordingly, $79 \%$ of the subjects had low self-management, and $21 \%$ had high self-management level.

\section{Discussion}

In the present study, the independent t-test showed a significant difference between marital status and total self-management $(\mathrm{P}<0.05)$, indicating that married patients have higher self-management than single ones. This finding was also supported by Tol et al. (2012) study, which showed a significant relationship between marital status and self-management $(\mathrm{P}<0.04)$. Similarly, Rahimian Booger et al. (2010) showed a significant relationship between marital status and self-management of diabetes. Given these results, marital status can have an impact on self-management behaviors, considering the supporting role of the spouse in changing lifestyles. In fact, married people have a relatively stable source of social support in contrast to single people who provide self-care. Also, the results of study by Walker et al. (2012) showed that

Table 6. Self-management level of patients

\begin{tabular}{ccc}
\hline Total Self-Management & Frequency & Percentage \\
\hline Low & 79 & 79 \\
High & 21 & 21 \\
\hline
\end{tabular}


married people control their illness better. However, the study by Yadollahi et al. (2015) reported that patients who live alone have a higher score in self-management behaviors than those who live with others.

The Pearson test results indicated a significant inverse relationship between age and self-management $(\mathrm{P}<$ $0.05)$. This means that total self-management reduces with increasing age. The study results also showed that age had a significant and negative relationship with the self-management of participants. This may be due to the fact that people's self-management is affected by age, complications, and treatment. Based on Yadollahi et al. (2015) study, there was no significant relationship between epileptic people's self-management score with epilepsy and age, while in McAuley et al. (2008) study, older people had higher self-management scores.

In the study by Yadollahi et al. (2015), there was a significant relationship between safety self-management and the level of education. Having more information, more educated individuals are more capable of controlling and managing their diseases than those with lower levels of education.

The results of the study by Aliasgharpour et al. (2013) also showed that before the educational intervention, the majority of participants in the study had an average level of self-management. The research results confirmed that due to the low level of self-management behaviors in most of the participants in the study, appropriate training regarding cognitive variables should be done in future studies. There was no specific limitation in this research. It is suggested to examine the impact of self-management education programs regarding the demographic variables in future programs.

\section{Acknowledgments}

This paper was extracted from the MSc. thesis of the fourth author in Department of Medical Surgical Nursing, School of Nursing and Midwifery, Iran University of Medical Sciences of Tehran. I acknowledge the staffs of Iran University of Medical Sciences, Iranian Epilepsy Association, Chancellor and the faculty members of Nursing and Midwifery, Iran University of Medical Sciences, and all the patients who participated in this study.

\section{Conflict of Interest}

The authors declared no conflicts of interest.

\section{References}

Aliasgharpour, M. et al., 2013. Effects of an educational program on self-management in patients with epilepsy. Seizure, 22(1), pp. 48-52. doi: 10.1016/j.seizure.2012.10.005

Akbarbegloo, M. et al., 2015. The Relationship between SelfEfficacy and Psychosocial Care in Adolescents with Epilepsy. Epilepsy Research and Treatment, 2015, pp. 1-7. doi: $10.1155 / 2015 / 756849$

Clark, N. M. et al., 2010. Fostering epilepsy self management: The perspectives of professionals. Epilepsy $\mathcal{E}$ Behavior, 19(3), pp. 255-63. doi: 10.1016/j.yebeh.2010.08.033

Edward, K., Cook, M. \& Giandinoto, J. A., 2015. An integrative review of the benefits of self-management interventions for adults with epilepsy. Epilepsy $\mathcal{E}$ Behavior, 45, pp. 195-204. doi: 10.1016/j.yebeh.2015.01.026

Fitzsimons, M. et al., 2012. Evidence-based models of care for people with epilepsy. Epilepsy $\mathcal{E}$ Behavior, 23(1), pp. 1-6. doi: 10.1016/j.yebeh.2011.10.019

Fraser, R.T. et al., 2011. Managing epilepsy well: Self-management needs assessment. Epilepsy E Behavior, 20(2), pp. 291298. doi: 10.1016/j.yebeh.2010.10.010

Hinkle J. L., \& Cheever K. H., 2014. Biophysical and psychosocial concepts in nursing practice. In: JL Hinkle \& KH Cheever (ed), Brunner E Suddarth's Textbook of Medical-Surgical Nursing [J Abed Saeidi \& H Esmaeili Persian trans]. Tehran: Jame'e Negar.

Mameniskiene, R., Sakalauskaite Juodeikiene, E. \& Budrys, V., 2015. People with epilepsy lack knowledge about their disease. Epilepsy \& Behavior, 46, pp. 192-7. doi: 10.1016/j. yebeh.2015.03.002

McAuley, J. W. et al., 2008. An evaluation of self-management behaviors and medication adherence in patients with epilepsy. Epilepsy $\mathcal{E}$ Behavior, 13(4), pp. 637-641. doi: 10.1016/j. yebeh.2008.07.005

Merianos, A. L. et al., 2014. Hospital, school, and communitybased strategies to enhance the quality of life of youth with chronic illness-es. Applied Research in Quality of Life, 10(2), pp. 329-42. doi: 10.1007/s11482-014-9311-9

Miller, W. R. et al., 2015. Chronic disease self-management: A hybrid concept analysis. Nursing Outlook, 63(2), pp. 154-61. doi: 10.1016/j.outlook.2014.07.005

Noble, A. et al., 2015. "Seizure first aid training" for people with epilepsy who attend emergency departments, and their family and friends: study protocol for intervention development and a pilot randomised controlled trial. BMJ Open, 5(7), p. e009040. doi: 10.1136/bmjopen-2015-009040

Pascual, F. T. et al., 2015. Outpatient education reduces emergency room use by patients with epilepsy. Epilepsy $\mathcal{E}$ Behavior, 42, pp. 3-6. doi: 10.1016/j.yebeh.2014.10.024

Rahimian Boogar, E., et al., 2010. [Diabetes self management: Social, demographical and disease factors (Persian)]. Journal of Clinical Psychology, 1(4), pp. 43-57.

Ratti, V. et al., 2016. The effectiveness of person-centred planning for people with intellectual disabilities: A systematic review. Research in Developmental Disabilities, 57, pp. 63-84. doi: 10.1016/j.ridd.2016.06.015 
Sawangchareon, K., et al., 2013. Moving the self-esteem of people with epilepsy by supportive group: A clinical trial. Journal of Caring Sciences, 2(4), pp. 329-35. doi: 10.5681/jcs.2013.039

Tol, A., et al., 2012. [Relation between empowerment of diabetes control and adoption of self-management behaviors and its related fac-tors among type 2 diabetic patients (Persian)]. Razi Journal of Medical Sciences, 19(98), pp. 11-8.

Walker, E. R. et al., 2012. Social support for self-management behaviors among people with epilepsy: A content analysis of the WebEase program. Epilepsy \& Behavior, 23(3), pp. 285-90. doi: 10.1016/j.yebeh.2012.01.006

Yadollahi, S. et al., 2015. [Correlation between Epilepsy SelfManagement Behaviors and Seizure Frequency among Patients with Epilepsy in Iran Epilepsy Association (Persian)] Preventive Care in Nursing \& Midwifery Journal, 5(1), pp. 59-70. 